\title{
Compatibility and correlation of multi-attribute decision making: a case of industrial relocation
}

\author{
Jose Martino Neto $^{1}$ (D) Valerio Antonio Pamplona Salomon ${ }^{1}$ (D) \\ Miguel Angel Ortiz-Barrios ${ }^{2}$ D $\cdot$ Antonella Petrillo ${ }^{3}$
}

Accepted: 14 February 2022

๑) The Author(s), under exclusive licence to Springer Science+Business Media, LLC, part of Springer Nature 2022

\begin{abstract}
Industrial relocation (IR) is a business strategy consisting of moving operations locations. The purpose of this paper is to present how to assess, with multi-attribute decision-making (MADM), alternatives for IR. With MADM, IR strategies can be assessed not only based on a single attribute, as costs, or profits. This paper presents the application of MADM in a real case of IR. Four leading methods of MADM were applied: analytic hierarchy process (AHP), multi-attribute utility theory (MAUT), multi-attribute value theory (MAVT), and technique of order preference by similarity to ideal solution (TOPSIS). Results of AHP, MAUT, MAVT, and TOPSIS were quite similar, indicating the decision for the company not to relocate. A joint comparison of results with compatibility indices and correlation coefficients is the major novelty presented by this paper to the field of Operations Research, known as MADM.
\end{abstract}

Keywords Analytic hierarchy process · Compatibility · Correlation · Industrial relocation · Multi-attribute utility theory - Technique of order preference by similarity to ideal solution

$凶$ Valerio Antonio Pamplona Salomon

valerio.salomon@unesp.br

Jose Martino Neto

martino56neto@gmail.com

Miguel Angel Ortiz-Barrios

mortiz1@cuc.edu.co

Antonella Petrillo

antonella.petrillo@uniparthenope.it

1 Department of Production, Sao Paulo State University, Av. Ariberto P. Cunha 333, Guaratingueta, SP 12516-410, Brazil

2 Department of Productivity and Innovation, Universidad de la Costa CUC, 58th Street \# 55-66, Barranquilla, Colombia

3 Department of Engineering, University of Naples Parthenope, Isola C4, Centro Direzionale, 80143 Naples, NA, Italy 


\section{Introduction}

Changes are part of daily life in business organizations. Competitiveness, pressure by stakeholders, sustainability issues, and supply chain variables, all force businesses to continually search for improvements (Arena et al., 2020; Jiang et al., 2018; Li \& Wang, 2020). Several strategies have been adopted to keep or to improve business. Industrial relocation (IR) is a business strategy consisting of moving operations locations. The choice for an IR strategy must consider benefits and opportunities, and also risks and threats of such a decision (Chen et al., 2018). Reduction in costs is usually an outstanding opportunity with IR. Moreover, IR may lead to better infrastructure, lower land costs, and other possible benefits granted by some cities, regions, or countries (Li et al., 2019; Tang et al., 2020). IR reinforces complementary advantages among different regions and promotes coordinated regional economic development (Zhang et al., 2020). However, many other aspects should be analyzed, regarding the complexity and the socio-economic impacts of moving a factory location (Pan et al., 2019; Yang \& Gallagher, 2017). IR plays a vital role in the promotion of economic growth, then IR has become a notable feature for the world's economic development (Wu et al., 2014).

The purpose of this paper is to guide decision-makers how to assess alternatives for IR by using multi-attribute decision-making (MADM). With MADM, IR strategies may be assessed not only based on a single attribute, as costs, or profits, but based on several attributes (OrtizBarrios \& Alfaro-Saiz, 2020). This paper presents the application of MADM methods in a real case of IR. The main motivation for this research was to verify the adherence of MADM to support decision-making on IR. The case of a metalworking plant located in Brazil, is a representative example, as presented in Sect. 4. Nevertheless, IR is not limited to a specific industry.

Four leading methods of MADM (Zavadskas et al., 2014) were applied: analytic hierarchy process (AHP), multi-attribute utility theory (MAUT), multi-attribute value theory (MAVT), and technique of order preference by similarity to the ideal solution (TOPSIS). AHP, MAUT, MAVT, and TOPSIS were applied with the same data, collected from a multinational company in the metal-mechanic industry. There is a trend for methods combination, in MADM literature (Ortiz-Barrios et al., 2020a). In this paper, MADM methods were not combined but fully applied and compared. Results from AHP, MAUT, MAVT, and TOPSIS applications were compared with compatibility indices (Garuti \& Salomon, 2012) and correlation coefficients (Salomon \& Rangel, 2015). Therefore, this paper presents more than a case study, combining mathematical modeling within a mixed research approach. With compatibility indices and correlation coefficients, it was expected to verify similarity among MADM methods. Compatibility is a measure of closeness (Lipovetsky, 2020), or similarity (Yoon, 2020), of decision vectors. Besides an emerging subject in AHP and MADM theories, literature on compatibility is deeply sparse. The joint analysis of compatibility and correlation of results from a real case is the major novelty of this paper.

The remainder of this paper is as follows. Section 2 presents a brief literature review on IR, mainly as a decision problem. Section 3 presents the research methodology, introducing MADM methods, compatibility indices, and correlation coefficients. Section 4 presents the case of MADM application in IR. Section 5 presents results from AHP, MAUT, MAVT, and TOPSIS, including their comparisons. Section 6 is dedicated to conclusions and an overview of the main findings. 


\section{Literature review}

Industrial diversification (ID) and industrial relocation (IR) are two dominant types of strategic responses to industrial decline (Grillitsch \& Asheim, 2018; Schamp, 2005). In ID, firms stay in the location but leave the industry. In IR, firms stay in the industry but leave the location. Therefore, IR is a strategy to increase business competitiveness by moving the location of its operations.

There are different tactics for IR, such as pseudo relocation, stratified relocation, and total relocation (Atakhan-Kenneweg et al., 2021; Brouwer et al., 2004). Pseudo relocation occurs by acquisitions or outsourcing of operations. Stratified relocation has been applied by manufacturers involving some segments of production (Johansson \& Olhager, 2017; Liao \& Chan, 2011). Total relocation is the focus of this paper. This IR tactic involves main driven forces including the need for more suitable premises, cost-saving, and policies incentives.

The main reasons for IR include environmental impacts (Aus Dem Moore et al., 2019; Koch \& Basse Mama, 2019; Li \& Wang, 2020; Li et al., 2019; Wang et al., 2019; Zhang et al., 2017), increasing land prices (Chen et al., 2018; Tang et al., 2020), manufacturing improvements (Jiang et al., 2018; Liu et al., 2021b), industrial restructuring (Kurata et al., 2020; Lundberg et al., 2016), shared value creation (Arena et al., 2020), and social-economic impacts (Indraprahasta et al., 2019; Pan et al., 2019; Pappas et al., 2018; Yang \& Gallagher, 2017).

Several methods have been applied to IR, like linear regression (Pappas et al., 2018; Tang et al., 2020), Monte Carlo simulation (Li \& Wang, 2020), non-linear regression (Wang et al., 2019), and percolation theory (Jiang et al., 2018). Those methods are pure mathematical modeling. MADM, instead requires human input, for instance to weight attributes. Human interaction is a major strength of MADM over regression and simulation models since this allows subjectiveness to be incorporated in problem-solving. MADM is gaining attention thanks to the possibility of tackling conflicting interests in very complex problems (Mardani et al., 2015b; Ortiz-Barrios et al., 2020a).

Applications of MADM methods were not found in relocation problems. There are applications of MADM for industrial location (Farahani et al., 2010), but not for relocation problems. In an extensive literature review of AHP applications (Vaidya \& Kumar, 2006), "allocations" is a major theme. However, no relocation application was referred. Their seven references on this theme were delimited to the problem of first location design or selection. An upper-todate AHP review (Emrouznejad \& Marra, 2017) did not apart "allocation" as an independent category. Likewise, several AHP applications on first location selection were included in the literature review.

A review of literature reviews (Zavadskas et al., 2014), undelimited to AHP, identified only one reference to the industrial location (Melo et al., 2009). Despite citing IR as "facility relocations", that reference did not associate IR with MCDM methods. Another upper-to-date literature review (Mardani et al., 2015a) also identified a single reference on the relocation problem. However, this reference presents AHP applied to a relocation problem of agricultural technology (Cay \& Yuan, 2013), not of industrial concern.

Therefore, there is a research gap in IR literature, since MADM and MCDM are well applied in several managerial decision problems, with emphasis on supply chain management (Ishizaka \& Nemery, 2013; Khan et al., 2018; Mardani et al., 2015b; Ortiz-Barrios et al., 2020a, 2020b; Tramarico et al., 2015). Then, the following research questions arise:

- Does MADM help managerial decision processes regarding IR?

- What MADM method can be applied to support IR? 
- Would applications of different methods of MADM result in the same decision?

Applications of MADM methods in a real case of IR are presented in Sect. 5. This is another novelty of this paper: MADM applied to IR. As previously observed, mathematical models such as linear or non-linear regression and simulation have already been applied in IR studies. One main disadvantage of those models compared to MADM is the requirement for historical data. With MADM, knowledge from experts may be incorporated into the analysis.

For MADM application, a set of attributes was collected from the literature cited in this section (Chen et al., 2018; Jiang et al., 2018; Li \& Wang, 2020; Liao \& Chan, 2011; Liu et al., 2021b; Pappas et al., 2018; Tang et al., 2020; Zhang et al., 2017):

- Attractive policy incentives.

- Environmental aspects.

- Labor shortage.

- Need to cut production costs.

- Physical proximity of high technology parks to industrial upgrading.

A five-component set of attributes may look too small for a strategic decision. However, size is not the most desirable characteristic of such a set. Mutually exclusiveness and collectively exhaustiveness (MECE) are the most desirable features for a set of attributes (Lee \& Chen, 2018). In this sense, the analysis of benefits, opportunities, costs, and risks (BOCR Model) has been successfully applied with AHP (Wijnmalen, 2007). With the BOCR Model, one can assess all factors to decision-making: The certain (B and C), uncertain (O and R), positive (B and O), and negative (C and R) merits (Shih et al., 2014). Therefore, four attributes, exclusive and exhaustive could be better than more attributes not exclusive, or nor exhaustive.

\section{Methodology}

\subsection{Generalities}

Multiple criteria decision-making (MCDM) is a methodology that applies conflicting criteria in the solution of decision problems (Doumpos \& Zopounidis, 2002). MCDM is divided into two branches (Farahani et al., 2010; Zavadskas et al., 2014): Multi-attribute decisionmaking (MADM) and multi-objective decision-making (MODM). Decision problems solved by MADM have a finite set of alternatives. In the extreme case, MADM deals with only two alternatives (Hwang \& Yoon, 1981; Lombardi Netto, et al., 2020). MODM deals with larger sets of alternatives. In the extreme case, MODM deals with infinite alternatives. Therefore, this paper is on MADM, since a finite set of alternatives will be considered in an IR problem. This is due to the nature of IR problems. Usually, IR deals with a limited set of alternatives, for example, cities, regions, or countries.

This paper proposes the application of MADM to solve a decision problem of IR. Figure 1 presents the four-step research flow.

For Step 1, IR may be defined as a "choice problem" (Ishizaka \& Nemery, 2013; Roy, 1981). In this type of decision problem, the goal is to select the single best alternative, or a subset of alternatives, as restricted as possible. In IR, the relocation to a single place is desirable. Then, IR, as the choice problem, refers to decisions of "winner-take-all" (Lee et al., 2006).

Step 2 started with attributes identification in Sect. 2. These attributes were confirmed by the case presented in Sect. 4, where alternatives were also identified. As this research aimed 


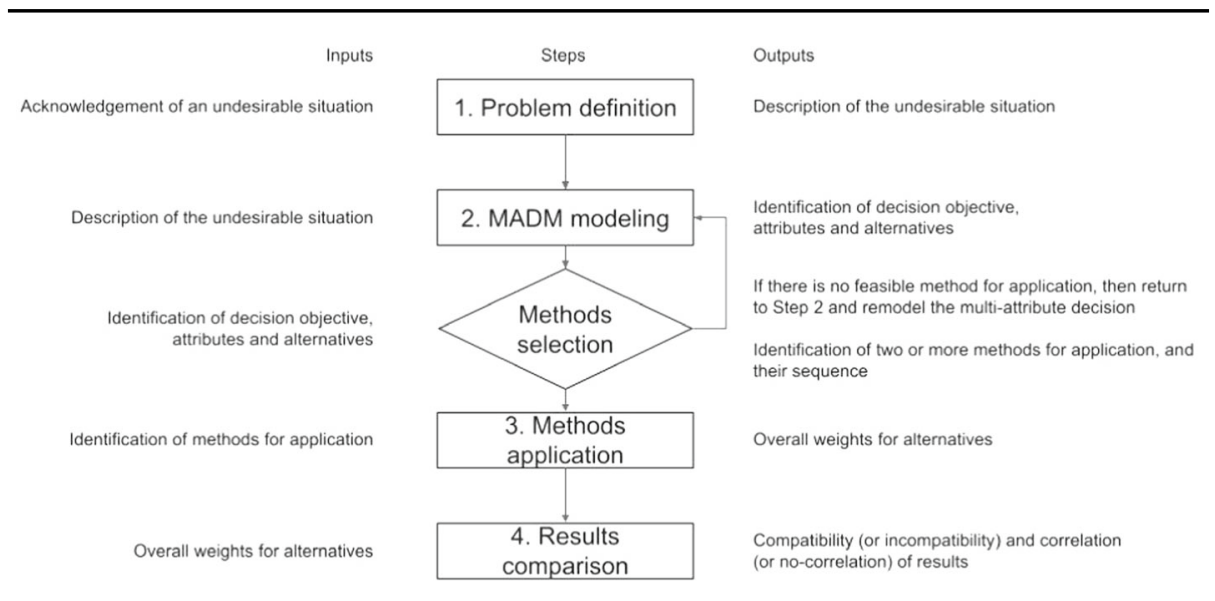

Fig. 1 Research flow

the comparison of different MADM methods, these methods were applied with the same model, i.e., the same sets of attributes and alternatives.

AHP, MAUT, MAVT, and TOPSIS were the selected MADM methods, at first, by their leadership in MADM literature (Khan et al., 2018; Wallenius, et al., 2008). AHP, MAUT, MAVT, and TOPSIS were mainly selected because they are MADM methods developed for the solution of a choice problem (Ishizaka \& Nemery, 2013). Besides some conceptual differences, all these methods result in decision vectors, $\boldsymbol{x}$, where $x_{i}$ is the overall priority (AHP), joint utility (MAUT), aggregate value (MAVT), or closeness coefficient (TOPSIS) for Alternative $i$. The best alternative is the one with the highest $x_{i}$.

Step 3 is presented in Sect. 5, with applications of AHP, MAUT, MAVT, and TOPSIS. Previously, in Sect. 4, the expert team is introduced. Four experts in the operations to be relocated provide input for MCDA. Results from methods application are presented in Sect. 5. Matter of fact, applications of different MADM methods may result in different decisions, even with the same data input (Liu et al., 2021a; Wang, 2015; Zamani-Sabzi et al., 2016; Zanakis et al., 1998; Zhang et al., 2015). Therefore, more than one MADM method will be applied and results compared, in the following step of this research.

Step 4 is presented in Sect. 5. The indication of the same best alternative from applications of two or more methods implies qualitatively similar results. Quantitative comparisons of results are also presented with two compatibility indices (Garuti and Saaty) and two correlation coefficients (Pearson and Spearman).

The remainder of this section presents concepts and details of MADM methods (Sects. 3.2 to 3.4), compatibility indices (Sect. 3.5), and correlation coefficients (Sect. 3.6).

\subsection{Analytic hierarchy process}

Developed by Saaty $(1974,1980)$, AHP is one the most applied MADM methods. There are AHP applications in diverse areas, like chemical engineering, computer science, ecology, energy sector, health sector, higher education sector, manufacturing, mathematical advances, supply chain management, and logistics (Emrouznejad \& Marra, 2017; Tramarico et al., 2015). 


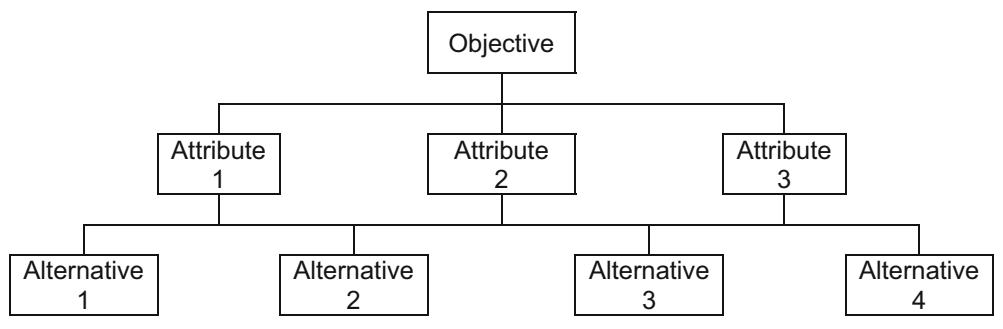

Fig. 2 Three-level hierarchy for a decision problem with three attributes and four alternatives

The first step for AHP application is to model the decision problem in a hierarchy (Saaty $\&$ Rogers, 1976). Decision objective in the top, $m$ attributes, usually named as criteria, in the middle of the hierarchy, and $n$ alternatives in the bottom. Figure 2 presents an example of a hierarchy model for $m=3$ and $n=4$.

The meaning of a hierarchical model is that the elements in a lower level need to be assessed regarding the elements in the higher level. Therefore, attributes shall be pairwise compared regarding decision objective, in this case, Industrial Relocation. Saaty Scale, more commonly referred to the Fundamental Scale of Absolute Numbers, as in Saaty (2013), is used in these pairwise comparisons. Saaty Scale is a linear 1-9 scale, with 1 for "equal importance", 3 for "weak importance of one over another", 5 for "strong importance", 7 for "very strong or demonstrated importance", and 9 for "absolute importance". Intermediate values, as 2, 4, 6, and 8, and even rational numbers may be used, if needed (Saaty \& Rogers, 1976).

Weights for the attributes, usually named as criteria priorities, are obtained normalizing the right eigenvector $\boldsymbol{w}$ of the pairwise comparison matrix $\boldsymbol{A}$, as in Eq. 1, where $\lambda_{\max }$ is its maximum eigenvalue.

$$
\boldsymbol{A} \boldsymbol{w}=\lambda_{\max } \boldsymbol{w}
$$

Consistency checking is one of the great advantages of AHP against other MADM methods. A consistent pairwise matrix $\boldsymbol{A}$ satisfies $a_{i j}=a_{i k} a_{k j}$, resulting in $\lambda_{\max }=m$. Consistency index $\mu$ is a measure of the consistency of a pairwise matrix, as in Eq. 2, where $m$ is the number of attributes.

$$
\mu=\frac{\lambda \max -m}{m-1}
$$

Consistency ratio $C R$ is a better measure since it compares $\mu$ with a random index $R I$, computed by Oak Ridge Laboratory with more than 50,000 matrices (Saaty, 1980), as in Eq. 3 .

$$
C R=\frac{\mu}{R I}
$$

Consistent matrices have $\lambda_{\max }=m$, then $\mu=0$ and $C R=0$. Inconsistent matrices have at least one comparison, and its reciprocal, $a_{i j} \neq a_{i k} a_{k j}$, resulting in $\lambda_{\max }>m$. It is desirable that $C R \leq 0.1$, then $\boldsymbol{A}$ may be accepted, meaning "conformity with previous practice" or that decision-makers did not change their minds, when fulfilling a pairwise comparison matrix.

Alternatives shall be assessed regarding each attribute, resulting in their importance, likelihood, membership, or preference $\boldsymbol{x}$. In AHP, these values of preferences are usually named as local priorities of alternatives (Saaty, 2013). 
Table 1 Standard levels for relative measurement in AHP

\begin{tabular}{ll}
\hline Level & Preference \\
\hline Excellent & 1.0 \\
Very good & 0.9 \\
Good & 0.8 \\
Average & 0.7 \\
Below average & 0.6 \\
Poor & 0.5 \\
Very poor & 0.4 \\
\hline
\end{tabular}

The same procedure may be used to obtain alternatives' preferences regarding each attribute. This original procedure was named "relative measurement" (Saaty, 2013). Conversely, in "absolute measurement", also named "ratings" (Saaty, 1986), alternatives are not pairwise compared to each other, instead of that, they are compared with standard levels (Salomon et al., 2016). Table 1 presents seven standard levels to assess alternatives regarding the attributes and proposal for their preference normalized in ideal synthesis (Salomon, 2016).

One first limitation of AHP is the required independence of alternatives and attributes. Another limitation is on the total of alternatives and attributes. If.

$m>9$, then attributes can be aggregated or grouped as sub-attributes which leads to one more level in the hierarchy. If $n>9$, alternatives can be grouped, or absolute measurement may be applied.

Overall priorities of alternatives $\boldsymbol{y}$ are obtained weighting local priorities of alternatives $\boldsymbol{x}$ by weights of attributes $\boldsymbol{w}$, as in Eq. 4 .

$$
y=w x
$$

\subsection{Multi-attribute utility and value theories}

MAUT is indicated when decision-makers can construct utility functions (Ishizaka \& Nemery, 2013; Oliveira \& Dias, 2020). With MAUT a large number of quantitative and qualitative attributes can be evaluated (Chang, 2009). It is an MADM simpler method AHP since MAUT does not require pairwise comparisons (Doczy \& AbdelRazig, 2017). Weights for attributes are directly assessed.

Preferences for alternatives come from utility functions $U$, with codomain in interval $[0,1]$. For each alternative, a marginal utility $\boldsymbol{u}$ shall be determined regarding each attribute. For qualitative attributes, a five-point adapted Likert Scale, as in Table 2, can be adopted. In Table 2 a sixth point was added, with Null.

This paper adopts linear utility functions, because they are simple to work, and because concepts as risks and uncertainty are not being considered. Then for instance, for three alternatives scored with 3, 4, and 5, from the Adapted Likert Scale, their marginal utilities are $U(3)=0, U(4)=0.5, U(5)=1$, respectively.

MAVT is a variation of MAUT with value functions $V$, instead of utility functions $U$ (Oppio et al., 2018). $U$ and $V$ have the same codomain: interval [0,1]. However, for each attribute, there will be always at least one alternative with $U=0$. In MAVT, zero marginal 
Table 2 Adapted Likert Scale for MAUT

\begin{tabular}{ll}
\hline Explanation & Score \\
\hline Excellent & 5 \\
Very good & 4 \\
Good & 3 \\
Fair & 2 \\
Poor & 1 \\
Null & 0 \\
\hline
\end{tabular}

values only result from null scores. Then, for Scores 3, 4, and 5, marginal values are $V(3)=$ $0.6, V(4)=0.8$, and $V(5)=1$, respectively.

\subsection{Technique of order preference by similarity to the ideal solution}

TOPSIS assesses the performances of alternatives through similarity with the ideal solution (Liern \& Pérez-Gladish, 2020). As in MAUT and MAVT, weights for attributes are directly assessed, without pairwise comparisons. For qualitative attributes, Table 2 also can be used in TOPSIS. The last similarity with MAUT and MAVT is on the use of values for preferences of alternatives $\boldsymbol{x}$. However, the decision matrix in TOPSIS has weighted values, as in Eq. 5, for $i=1, \ldots, m$, and $j=1, \ldots, n$.

$$
x_{i j}=w_{j} v_{i j}
$$

Besides the TOPSIS name referring to an ideal solution, this method also works with an anti-ideal solution, also referred to negative ideal solution (NIS). Positive ideal solution (PIS) $\boldsymbol{a}^{+}$, and NIS $\boldsymbol{a}^{-}$can be obtained as in Eqs. 6 and 7 , for $j=1, \ldots, m$.

$$
\begin{aligned}
& a_{j}^{+}=\max \left(x_{i j}\right) \\
& a_{j}^{-}=\min \left(x_{i j}\right)
\end{aligned}
$$

Then, Euclidean distances to NIS and PIS $\boldsymbol{d}^{-}$and $\boldsymbol{d}^{+}$must be obtained as in Eqs. 8 and 9 , for $i=1, \ldots, m$.

$$
\begin{aligned}
& d_{i}^{+}=\sqrt{\sum_{j=1}^{n}\left(a_{j}^{+}-x_{i j}\right)^{2}} \\
& d_{i}^{-}=\sqrt{\sum_{j=1}^{n}\left(x_{i j}-a_{j}^{-}\right)^{2}}
\end{aligned}
$$

Finally, closeness coefficients $c_{i}$ are obtained as in Eq. 10, for $i=1, \ldots, m$.

$$
c_{i}=\frac{d_{i}^{-}}{d_{i}^{-}+d_{i}^{+}}
$$

When overall preferences for Alternative $i$ are closer to PIS than NIS, then $c_{i}>0.5$. 


\subsection{Compatibility indices}

Decision vectors are the main expected result with AHP, MAUT, MAVT, and TOPSIS applications. They have different names and concepts as "overall priority" for AHP, "joint utility" for MAUT, and "aggregate value" for MAVT, and "closeness coefficient" for TOPSIS. However, there are also some common features. Components ranging from 0 to 1 are the main mathematical similarity of AHP's, MAUT's, MAVT's, and TOPSIS's decision vectors.

As previously mentioned in Sect. 3, applications of different MADM methods may result in different decisions (Zanakis et al., 1998). On the other hand, not identical decision vectors may lead to the same decision. Mathematically, different vectors may be close or far. When two different vectors are close, they are compatible vectors (Saaty, 2013). Saaty Compatibility Index $S$ between $\boldsymbol{x}$ and $\boldsymbol{y}$ is obtained as in Eq. 11, where $a_{i j}=x_{i} / x_{j}, b_{i j}=y_{i} / y_{j}, e_{i}=1$, and $\odot$ is the Hadamard Product operator, $a_{i j} \odot b_{i j}^{\mathrm{T}}==a_{i j} b_{j i}$, for $i=1, \ldots, m$ and $j=1, \ldots, m$.

$$
S=\frac{1}{m^{2}} \boldsymbol{e}^{\mathrm{T}} \boldsymbol{A} \odot \boldsymbol{B}^{\mathrm{T}} \boldsymbol{e}
$$

The codomain of $S(\boldsymbol{x}, \boldsymbol{y})$ is interval [1, $+\infty$ [. Identical vectors $\boldsymbol{x}=\boldsymbol{y}$ result in $S=1$. Otherwise $S>1$. For $3 \leq m \leq 5$, Saaty (2013) suggests that $S \leq 1.1$ indicates compatibility between $\boldsymbol{x}$ and $\boldsymbol{y}$.

Garuti Compatibility Index $G$, between $\boldsymbol{x}$ and $\boldsymbol{y}$, is obtained as in Eq. 12 .

$$
G=\sum_{i=1}^{m}\left[\frac{\min \left(x_{i}, y_{i}\right)}{\max \left(x_{i}, y_{i}\right)} \frac{\left(x_{i}+y_{i}\right)}{2}\right]
$$

The codomain of $G(\boldsymbol{x}, \boldsymbol{y})$ is interval $[0,1]$. Identical vectors $\boldsymbol{x}=\boldsymbol{y}$ also result in 1 for this compatibility index, or in $G=1$. Otherwise $G<1$. Ten-percent tolerance was also proposed for $G$, as in Garuti (2019).

For $n>5, S$ is not indicated due to the sensibility to small components in $\boldsymbol{x}$ and $\boldsymbol{y}$. Garuti and Salomon (2012) presented two examples of validated AHP applications: distance of six cities to Philadelphia (Saaty, 1977) and electricity consumption by seven common household appliances (Whitaker, 2007). The example of distance estimation was also studied by Lipovetsky (2020), but not by Yoon (2020), which are two of the most recent works on compatibility indices. Lipovestky (2020) included indices $G$ and $S$, whereas Yoon (2020) limited to index $S$.

For the distance estimation example, both indices $G$ and $S$ indicate compatible vectors. For the energy consumption example, $S \approx 1.46$ and $G \approx 0.92$. Therefore, indices $G$ and $S$ diverge on compatibility: they are compatible vectors, according to $G$, but incompatible vectors, according to $S$. AHP and real-distance vectors resulted in the same decision for the choice problem and the ranking problem. Garuti and Salomon (2012) concluded that $G$ and $S$ performed equally well for the example of distances to cities, but $G$ performed better for the example of electricity consumption. Only two cases are too few to generalize one index superiority over another. This paper contributes to this literature with a new case. 


\subsection{Correlation coefficients}

From Statistics, variance $\operatorname{var}(\boldsymbol{x})$ is a measure of one variable $\boldsymbol{x}$ variation, obtained as in Eq. 13, where $\bar{x}$ is the average, or arithmetic mean of $x_{i}$, for $i=1, \ldots, m$.

$$
\operatorname{var}(\boldsymbol{x})=\frac{1}{m} \sum_{i=1}^{m}\left(x_{i}-\bar{x}\right)^{2}
$$

Covariance $\operatorname{cov}(\boldsymbol{x}, \boldsymbol{y})$ is a measure of joint variation between two variables, $\boldsymbol{x}$ and $\boldsymbol{y}$ (Rice, 2007), obtained as in Eq. 14.

$$
\operatorname{cov}(\boldsymbol{x}, \boldsymbol{y})=\frac{1}{m} \sum_{i=1}^{m}\left[\left(x_{i}-\bar{x}\right)\left(y_{i}-\bar{y}\right)\right]
$$

Correlation is the degree of association between two variables (Asuero et al., 2006). Pearson correlation coefficient $r$ between $\boldsymbol{x}$ and $\boldsymbol{y}$ is obtained as in Eq. 15 .

$$
r=\frac{\operatorname{cov}(\boldsymbol{x}, \boldsymbol{y})}{\sqrt{\operatorname{var}(\boldsymbol{x}) \operatorname{var}(\boldsymbol{y})}}
$$

The codomain of $r(\boldsymbol{x}, \boldsymbol{y})$ is interval [-1, 1]. Identical vectors $\boldsymbol{x}=\boldsymbol{y}$ result in $r=1$, referred to the perfect correlation between $\boldsymbol{x}$ and $\boldsymbol{y}$. Additionally, $r=0$ means that there is no correlation between $\boldsymbol{x}$ and $\boldsymbol{y}$, and $r<0$ results when there is a negative correlation between $\boldsymbol{x}$ and $\boldsymbol{y}$.

MADM deals with a finite number of alternatives. When the set of alternatives was little, for instance $n=2,3,4$, there is a mathematical concerning with the use of $r$. Correlation of too few observations may be unreliable. Therefore, that correlation should be checked by its statistical significance of the difference from zero, initially by calculating $t_{r}$, as in Eq. 16 .

$$
t_{r}=\frac{r \sqrt{n-2}}{\sqrt{1-r^{2}}}
$$

Then, it will be possible not only to indicate where such a correlation is higher or lower, but also it will be possible to test the quantitative reliability of the resulted value for $r$. There are different statistical tests on the significance of correlation indices. This paper employs the Student's $t$-distribution. In the two-tailed $t$-distribution, the significance level of $\alpha=0.1$, results in $t=2.92$. Therefore, for $t_{r} \geq 2.92, r$ can be considered a reliable correlation index, with a probability at least equals to $90 \%$ (Venables \& Ripley, 2002).

Spearman rank correlation coefficient $r_{s}$ between $\boldsymbol{x}$ and $\boldsymbol{y}$ is obtained as in Eq. 17, where $p_{i}=\operatorname{rank}\left(x_{i} \mid \boldsymbol{x}\right), q_{i}=\operatorname{rank}\left(y_{i} \mid \boldsymbol{y}\right)$, for $i=1, \ldots, m$.

$$
r_{s}=\frac{\operatorname{cov}(\boldsymbol{p}, \boldsymbol{q})}{\sqrt{\operatorname{var}(\boldsymbol{p}) \operatorname{var}(\boldsymbol{q})}}
$$

\section{Case study}

A French industrial group has one of its major plants located in the municipality of Sao Paulo, the capital city of the state of Sao Paulo. This partially automated plant, with 400 employees, transforms 6000 tons of raw material into metal-mechanics products, annually. The group strategic plan identified the need for cost reductions of operations in Brazil. Therefore, the board of directors of the group considered relocating this plant. 
Table 3 Attributes identified by the French group for industrial relocation

\begin{tabular}{ll}
\hline Attribute & Definition \\
\hline Environment (E) & Satisfaction of environmental issues, defined by local and national regulations \\
Infrastructure (I) & Availability and costs of electricity, gas, water, etc. \\
Transportation (T) & Easiness to receive and send materials to airports, roads, and seaports \\
Workers (W) & Availability and costs of direct manpower \\
\hline
\end{tabular}

The option of relocating the plant came from a sum of factors: The high cost of direct labor and respective fringe benefits; the high rental price of real estate for the plant site; understanding that the plant has reached the maximum operational efficiency, using all Lean Manufacturing concepts and tools. Another important factor was the decreasing competitiveness due to the launch of new products manufactured in China.

Table 3 presents the main attributes identified to this strategic decision.

The five attributes identified in the literature review (Sect. 2) were combined in Attributes E, I, T, and W, with the "Need to cut production costs." as a decision objective. E, I, T, and W is a four-element set of attributes. This set is mutually exclusive and collectively exhaustive since all elements of BOCR are considered. Environment is related to Risks, Infrastructure relates to Benefits, Transportation relates to Opportunities, and Workers relates to Costs.

Environment is a major issue nowadays. Brazil is at the center of several controversies. Forest fires and dam accidents have gained international repercussions in recent years. Fortunately, this is not the case of the studied company, which operates in the secondary sector of the economy. In other words, industries are not the greatest source of concern with Brazilian environmental laws. In that way, Infrastructure could be a more important criterion to guide an industrial relocation decision. However, as presented further in this section, every alternative considered for relocation has, at least, good infrastructure, in terms of electric power, gas and oil distribution, and also water and waste management.

Transportation is a major issue due to the Brazilian continental dimension. Ground transportation on paved highways is the primary modal for cargo and passengers. Rail and river transport is rarely used, as the air network is in full development. With more than 4000 airports and landing fields, Brazil has the second-largest network, only after the United States (Central Intelligence Agency, 2021).

Manpower for operating the plant only needs basic skills. They do not require a degree from a higher-level course. On the other hand, technical professionals, trained in the operation of machine tools, such as cutting and milling, are highly desirable.

Figure 3 presents a blank map of Brazil, with states borders. Four locations were identified from the company's internal reports and surveys, referred by their airport codes: Recife (REC), Rezende (QRZ), Sao Jose dos Campos (SJK), and Sao Paulo (GRU). GRU and REC are two Brazilian top-ten populous cities. The other eight cities are included in red. The major Brazilian industrial districts are located in those cities.

The current location (GRU) is considered as an alternative. Still, this is a case of industrial relocation and not a case of industrial diversification. After all, even if the company chooses GRU, their products will be the same as the metal-mechanics industry.

Table 4 presents an assessment based on the company's reports on the four alternatives, regarding the four attributes. 


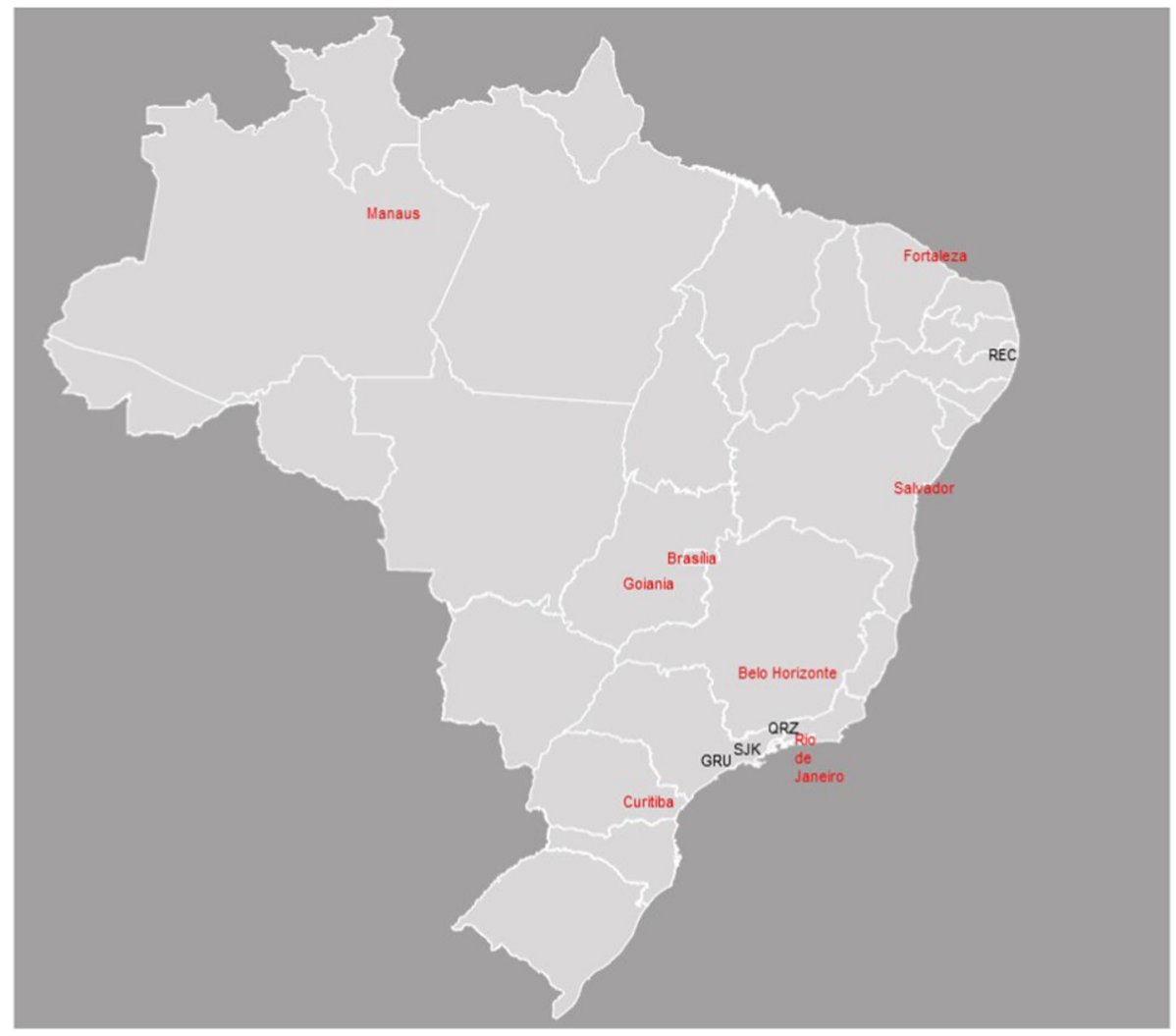

Fig. 3 Alternatives for industrial relocation ( Source: Wikimedia Commons, 2008)

Table 4 Alternatives assessment from company's reports

\begin{tabular}{lllll}
\hline Alternative & E & I & T & W \\
\hline GRU & Regular & Good & Very good & Excellent \\
QRZ & Good & Excellent & Good & Good \\
REC & Excellent & Excellent & Regular & Medium \\
SJK & Excellent & Very good & Good & Very good \\
\hline
\end{tabular}

A team of experts in the plant operations was identified to provide data for the MADM application. The team of experts was composed of four persons:

- Industrial Director, responsible for all activities in South America four plants, 35 years of experience in the company.

- Senior Manufacturing Manager, responsible for two plants in Brazil, 25 years of experience.

- Senior Supply Chain Manager, responsible for all logistic operations in South America, 20 years of experience. 
- Senior Engineering Manager, 18 years of experience in multinational companies.

This is the first MADM or MCDM application in a strategic decision by the French industrial group in Brazil. Therefore, the team of experts in plant operations was firstly introduced to MCDM general concepts. Then, details in AHP, MAUT, MAVT, and TOPSIS were presented as their applications evolved.

This is not group decision-making (GDM), as defined by Mu et al. (2020). Therefore, instead of each member of the team of experts providing a single, data were provided by consensus, in a single meeting. Then, aggregation was not an issue. On the other hand, as presented in Sect. 5, consistency indices of pairwise comparison matrices were quite satisfactory, under the 0.10 threshold.

\section{Results}

\subsection{Application of AHP}

Table 5 presents a pairwise comparisons matrix of attributes for industrial location. Weights were obtained with the normalized right eigenvector of the comparison matrix.

The comparison matrix presented in Table 5 may be accepted, since its $\lambda_{\max } \approx 4.11$,

$\mu \approx 0.040$, and $C R=0.044$. Table 6 presents local and overall priorities of alternatives for industrial relocation. Local priorities are obtained associating assessment from Table 4 with preferences from Table 1.

AHP application resulted in the highest overall priority for GRU. Then, the decision is not to relocate the plant from Sao Paulo (GRU). The second-best decision, relocate to Sao Jose dos Campos (SJK) is only 0.031 overall points behind GRU. Relocate to Recife (REC) or Rezende (QRZ) are also good decisions, with overall priorities higher than 0.8 and 0.7 , respectively.

Table 5 Comparisons and weights of attributes for industrial relocation

\begin{tabular}{llllll}
\hline Attribute & $\mathrm{E}$ & $\mathrm{I}$ & $\mathrm{T}$ & $\mathrm{W}$ & Weight $(\%)$ \\
\hline Environment (E) & 1 & 3 & $1 / 3$ & $1 / 5$ & 12 \\
Infrastructure (I) & $1 / 3$ & 1 & $1 / 5$ & $1 / 7$ & 6 \\
Transportation (T) & 3 & 5 & 1 & $1 / 3$ & 26 \\
Workers (W) & 5 & 7 & 3 & 1 & 56 \\
\hline
\end{tabular}

Table 6 Local and overall priorities of alternatives for industrial relocation

\begin{tabular}{llllll}
\hline Alternative & $\mathrm{E}$ & $\mathrm{I}$ & $\mathrm{T}$ & $\mathrm{W}$ & Overall \\
\hline GRU & 0.6 & 0.8 & 0.9 & 1.0 & 0.914 \\
QRZ & 0.8 & 1.0 & 0.8 & 0.8 & 0.812 \\
REC & 1.0 & 1.0 & 0.6 & 0.7 & 0.728 \\
SJK & 1.0 & 0.9 & 0.8 & 0.9 & 0.886 \\
\hline
\end{tabular}




\subsection{Applications of MAUT and MAVT}

For MAUT, MAVT and TOPSIS applications weights of attributes should be the same as AHP's priorities. After all, this paper aims to compare results from the applications of different MADM methods.

Table 7 presents scores of alternatives for industrial relocation, obtained associating assessment from Table 4 with scores from the adapted Likert Scale (Table 2).

Table 8 presents marginal and joint utilities of alternatives for industrial relocation, obtained with linear utility functions of scores presented in Table 7.

MAUT application resulted in the highest joint utility for GRU. Therefore, the same decision from the AHP application: not to relocate the plant from Sao Paulo. Relocate to Sao Jose dos Campos (SJK) comes second, and relocation to Recife (REC) and Rezende (QRZ) had joint utilities lower than 0.5. This means that relocating to QRZ or REC might be not satisfying, considering the whole set of attributes.

Table 9 presentsmarginal and aggregate values of alternatives for industrial relocation. Marginal values $v_{i j}$ obtained normalizing scores $s_{i j}$ presented in Table 7 , as $v_{i j}=$ $s_{i j} / \max _{i=1}^{m} s_{i j}$.

Table 7 Scores of alternatives for industrial relocation

\begin{tabular}{lllll}
\hline Alternative & E & I & T & W \\
\hline GRU & 1 & 3 & 4 & 5 \\
QRZ & 3 & 5 & 3 & 3 \\
REC & 5 & 5 & 2 & 3 \\
SJK & 5 & 4 & 3 & 4 \\
\hline
\end{tabular}

Table 8 Marginal and joint utilities of alternatives for industrial relocation

\begin{tabular}{llllll}
\hline Alternative & E & I & T & W & Joint \\
\hline GRU & 0 & 0 & 1 & 1 & 0.820 \\
QRZ & 0.5 & 1 & 0.5 & 0 & 0.250 \\
REC & 1 & 1 & 0 & 0 & 0.180 \\
SJK & 1 & 0.5 & 0.5 & 0.5 & 0.560 \\
\hline
\end{tabular}

Table 9 Marginal and aggregate values of alternatives for industrial relocation

\begin{tabular}{llllll}
\hline Alternative & $\mathrm{E}$ & $\mathrm{I}$ & $\mathrm{T}$ & $\mathrm{W}$ & Aggregate \\
\hline GRU & 0.2 & 0.6 & 1 & 1 & 0.880 \\
QRZ & 0.6 & 1 & 0.75 & 0.6 & 0.663 \\
REC & 1 & 1 & 0.5 & 0.6 & 0.646 \\
SJK & 1 & 0.8 & 0.75 & 0.8 & 0.811 \\
\hline
\end{tabular}


Table 10 Decision matrix for TOPSIS

\begin{tabular}{lllll}
\hline Alternative & E & I & T & W \\
\hline GRU & 0.024 & 0.036 & 0.260 & 0.560 \\
QRZ & 0.072 & 0.060 & 0.195 & 0.336 \\
REC & 0.120 & 0.060 & 0.130 & 0.336 \\
SJK & 0.120 & 0.048 & 0.195 & 0.448 \\
\hline
\end{tabular}

Table 11 Euclidean distances to NIS and PIS, and closeness coefficients of alternatives for industrial relocation

\begin{tabular}{llll}
\hline Alternative & $\boldsymbol{d}^{+}$ & $\boldsymbol{d}^{-}$ & $\boldsymbol{c}$ \\
\hline GRU & 0.099 & 0.259 & 0.723 \\
QRZ & 0.238 & 0.084 & 0.261 \\
REC & 0.259 & 0.099 & 0.277 \\
SJK & 0.130 & 0.162 & 0.555 \\
\hline
\end{tabular}

MAVT application results in the highest aggregate for GRU. Therefore, the same decision from AHP and MAUT applications: not to relocate the plant from GRU. Relocate to SJK comes second, relocate to QRZ in third, and relocate to QRZ in fourth and last. With all aggregate values higher than 0.5 , relocation to all these cities may be valuable, considering the whole set of attributes.

\subsection{Application of TOPSIS}

Table 10 presents the decision matrix for TOPSIS, obtained with the decision matrix for MAVT with values weighted by the attribute's weights.

Table 11 presents Euclidean distances to NIS and PIS, respectively $\boldsymbol{d}^{+}$and $\boldsymbol{d}^{-}$, and also presents closeness coefficients $\boldsymbol{c}$ of alternatives for industrial relocation.

TOPSIS application resulted in the highest closeness coefficient for GRU. Therefore, the same decision from AHP and MAUT applications: not to relocate the plant from GRU. Relocate to SJK comes second, relocation to QRZ and REC had closeness coefficients lower than 0.5 . This means that relocating to QRZ or REC might be not valuable, considering the whole set of attributes.

\subsection{Qualitative comparison of MADM applications}

Table 12 summarizes the results of AHP, MAUT, MAVT, and TOPSIS applications. GRU's highest priority, utility, value, or closeness are highlighted in italics. QRZ's and REC's lower than 0.5 utility and closeness had bold because they are alternatives to be avoided according to MAUT and TOPSIS.

The same decision results from the four MADM methods: not to relocate the industrial plant from GRU. AHP, MAUT, and MAVT applications resulted in the same ranks: first GRU, second SJK, third QRZ, and fourth REC. With TOPSIS, REC was ranked third, and QRZ ranked fourth. 
Table 12 Results of different MADM methods applications to industrial relocation

\begin{tabular}{lllll}
\hline Alternative & AHP & MAUT & MAVT & TOPSIS \\
\hline GRU & 0.914 & 0.820 & 0.880 & 0.723 \\
QRZ & 0.812 & $\mathbf{0 . 2 5 0}$ & 0.663 & $\mathbf{0 . 2 6 1}$ \\
REC & 0.728 & $\mathbf{0 . 1 8 0}$ & 0.646 & $\mathbf{0 . 2 7 7}$ \\
SJK & 0.886 & 0.560 & 0.811 & 0.555 \\
\hline
\end{tabular}

Table 13 Saaty compatibility indices of different MADM methods applications to industrial relocation

\begin{tabular}{lllll}
\hline Method & AHP & MAUT & MAVT & TOPSIS \\
\hline AHP & 1 & 1.301 & 1.004 & 1.139 \\
MAUT & 1.301 & 1 & 1.248 & 1.045 \\
MAVT & 1.004 & 1.248 & 1 & 1.099 \\
TOPSIS & 1.139 & 1.045 & 1.099 & 1 \\
\hline
\end{tabular}

Table 14 Garuti compatibility indices of different MADM methods applications to industrial relocation

\begin{tabular}{lllll}
\hline Method & AHP & MAUT & MAVT & TOPSIS \\
\hline AHP & 1 & 0.647 & 0.952 & 0.723 \\
MAUT & 0.647 & 1 & 0.680 & 0.895 \\
MAVT & 0.952 & 0.680 & 1 & 0.758 \\
TOPSIS & 0.723 & 0.895 & 0.758 & 1 \\
\hline
\end{tabular}

Summarizing all four methods led to the same decision. Almost the same ranks resulted from the four applications. AHP and MAVT were more benevolent with the last alternatives than MAUT and TOPSIS.

\subsection{Quantitative comparison of MADM methods}

Table 13 presents Saaty Compatibility Indices $S$ between the results of AHP, MAUT, MAVT, and TOPSIS. Indices $S$ between AHP and MAVT, and between MAUT and TOPSIS are highlighted in italics, because they are lower than the upper limit of 1.1, indicating compatibility between those pairs of methods.

Table 14 presents Garuti compatibility indices $G$ between the results of AHP, MAUT, MAVT, and TOPSIS. Indices $G$ between AHP and MAVT, and between MAUT and TOPSIS are also highlighted in italics, because they are greater than the lower limit of 0.9 .

According to Tables 13 and 14, results from AHP and MAVT, and from MAUT and TOPSIS are compatible. Even resulting in the same decision of not relocating from Sao Paulo, results from AHP and MAUT, from MAUT and MAVT and from AHP and TOPSIS are indicated as not compatible by both indices $G$ and $S$. 
Table 15 Pearson correlation coefficients of different MADM methods applications to industrial relocation

\begin{tabular}{lllll}
\hline Method & AHP & MAUT & MAVT & TOPSIS \\
\hline AHP & 1 & 0.925 & 0.930 & 0.887 \\
MAUT & 0.925 & 1 & 0.992 & 0.990 \\
MAVT & 0.930 & 0.992 & 1 & 0.994 \\
TOPSIS & 0.887 & 0.990 & 0.994 & 1 \\
\hline
\end{tabular}

Table 16 Testing results for Pearson correlation coefficients

\begin{tabular}{lcccc}
\hline Method & AHP & MAUT & MAVT & TOPSIS \\
\hline AHP & & 3.443 & 3.578 & 2.716 \\
MAUT & 3.443 & & 11.11 & 9.925 \\
MAVT & 3.578 & 11.11 & & 12.85 \\
TOPSIS & 2.716 & 9.925 & 12.85 & \\
\hline
\end{tabular}

Table 17 Spearman rank correlation coefficients of different MADM methods applications to industrial relocation

\begin{tabular}{lllll}
\hline Method & AHP & MAUT & MAVT & TOPSIS \\
\hline AHP & 1 & 1 & 1 & 0.8 \\
MAUT & 1 & 0.8 & 1 & 0.8 \\
MAVT & 1 & 1 & 1 & 0.8 \\
TOPSIS & 0.8 & 0.8 & 0.8 & 1 \\
\hline
\end{tabular}

Table 15 presents Pearson correlation coefficients $r$ between the results of AHP, MAUT, MAVT, and TOPSIS. Coefficient $r$ between AHP and TOPSIS is highlighted in italics because it is the only lower than 0.9 .

Table 16 presents $t_{r}$ values computed for $r$ presented in Table 15.

As in Table 15, less correlated pair AHP-TOPSIS had the lower value for $t_{r}$, and the only $t_{r}<2.92$. Therefore, for AHP-TOPSIS correlation is the only not reliable, as presented in Sect. 3.5.

Table 17 presents Spearman rank correlation coefficients $r_{s}$ between the results of AHP, MAUT, MAVT, and TOPSIS. Coefficients $r$ between TOPSIS and other methods are highlighted in italics because they are lower than 0.8 .

According to results from AHP, MAUT and MAVT are perfectly correlated, resulting in the same ranks. Results from TOPSIS are poorly correlated with the others, in this case.

\subsection{Managerial implications}

The applications of all four methods resulted in the same decision for the company: not to relocate from GRU. Moreover, this indication came from a multi-attribute model analyzed 
by different methods, i. e., considering diverse concepts such as Euclidean distance, priority, utility, and value. This unanimity reinforces and justifies the decision-making.

External and internal factors led the company's top management to consider industrial relocation. Therefore, four major attributes were identified in the international literature for IR decisions: environmental, infrastructure, transportation, and workers. Company top managers assessed the attributes in a single meeting. With AHP their opinion was proved to have consistency, which was very welcomed by them. Therefore, managers are interested in applying AHP for other strategical decisions.

After collecting data from feasible locations, the decision of not relocating surprised managers, at a first glance. However, with the application of four different methods resulting the same, managers were convinced that was not the time for a strategic change as the industrial relocation.

After the application of MADM methods, but before the writing of this paper, the company decided to implement the decision. They announced to keep the plant located in Sao Paulo.

\section{Conclusions}

This paper presents a real-world case of industrial relocation (IR) solved by the applications of four MADM methods. The pre-COVID-19 case considered the relocation of an industrial plant in Sao Paulo to three other locations. However, considering attributes from IR literature, all four MADM methods result in not moving the plant from Sao Paulo. All methods resulted in Sao Jose dos Campos as the second location. Recife and Rezende resulted as good options for AHP and MAVT, but not for MAUT and TOPSIS.

The alternative of not relocating from Sao Paulo had the highest overall results as 0.914 overall priority with AHP, 0.820 joint utility with MAUT, 0.880 aggregate value with MAVT, and 0.723 closeness coefficient to the ideal solution with TOPSIS. On the other hand, alternatives to relocate to Recife or Rezende had joint utilities far lower than 0.5, indicating alternatives to be not considered, if the first alternative becomes unavailable.

Results were compared with compatibility indices and correlation coefficients. Results with AHP and MAVT were indicated as compatible and correlated. Results from TOPSIS had a lower compatibility correlation with results from other methods.

Hybridism is a trend in MADM and MCDM. This paper presents the use of compatibility indices and correlation coefficients, with concepts and indicators to promote discussion on results from different methods. Matter of fact, applications of different methods resulted in the same decision: Not relocate the plant. Ranks of the alternatives were also considered, even being not important result in this case. This consideration just emphasized the similarity of the results. Moreover, this analysis may be useful for future research.

Applications of new methods of MADM, as Best Worst Method (BWM), Complex Proportional Assessment (COPRAS), Potentially All Pairwise Rankings of all Possible Alternatives (PAPRIKA), or Visekriterijumska Optimizacija I Kompromisno Resenje (VIKOR) emerge as first sources for researches. Incorporating techniques as Delphi and Fuzzy may be useful if more alternatives or uncertainty were present in the decision problem. Additionally, it can be considered the inclusion of other attributes, dealing with political or social issues. Finally, the proposed methodology may be replicated in other industries. 


\section{References}

Arena, M., Azzone, G., \& Piantoni, G. (2020). Shared value creation during site decommissioning: A case study from the energy sector. Journal of Cleaner Production. https://doi.org/10.1016/j.jclepro.2019.119587

Asuero, A. G., Sayago, A., \& González, A. G. (2006). The correlation coefficient: An overview. Critical Reviews in Analytical Chemistry, 36(1), 41-59. https://doi.org/10.1080/10408340500526766

Atakhan-Kenneweg, M., Oerlemans, L. A., \& Raab, J. (2021). New inter-organizational knowledge tie formation after firm relocation: Investigating the impact of spatial, relational, and temporal context. Journal of Business Research, 127, 264-276. https://doi.org/10.1016/j.jbusres.2021.01.023

Aus Dem Moore, N., Großkurth, P., \& Themann, M. (2019). Multinational corporations and the EU Emissions Trading System: The specter of asset erosion and creeping deindustrialization. Journal of Environmental Economics and Management, 94, 1-26. https://doi.org/10.1016/j.jeem.2018.11.003

Brouwer, A. E., Mariotti, I., \& Van Ommeren, J. N. (2004). The firm relocation decision: An empirical investigation. The Annals of Regional Science, 38(2), 335-347. https://doi.org/10.1007/s00168-004-0198-5

Cay, T., \& Yuan, M. (2013). Evaluation of reallocation criteria in land consolidation studies using the Analytic Hierarchy Process (AHP). Land Use Policy, 30(1), 541-548. https://doi.org/10.1016/j.landusepol.2012. 04.023

Central Intelligence Agency. (2021). The World Factbook 2021. Retrieved June 18, 2021, from https://www. cia.gov/the-world-factbook/

Chang, W.-L. (2009). Using multi-criteria decision aid to rank and select co-branding partners: From a brand personality perspective. Kybernetes, 38(6), 950-965. https://doi.org/10.1108/03684920910973171

Chen, W., Shen, Y., Wang, Y., \& Wu, Q. (2018). The effect of industrial relocation on industrial land use efficiency in China: A spatial econometrics approach. Journal of Cleaner Production, 205, 525-535. https://doi.org/10.1016/j.jclepro.2018.09.106

Doczy, R., \& AbdelRazig, Y. (2017). Green buildings case study analysis using AHP and MAUT in sustainability and costs. Journal of Architectural Engineering, 23(3), 05017002. https://doi.org/10.1061/ (ASCE)AE.1943-5568.0000252

Doumpos, M., \& Zopounidis, C. (2002). Multicriteria decision aid classification methods. Kluwer.

Emrouznejad, A., \& Marra, M. (2017). The state of the art development of AHP (1979-2017): A literature review with a social network analysis. International Journal of Production Research, 55(22), 6653-6675. https://doi.org/10.1080/00207543.2017.1334976

Farahani, R. Z., SteadieSeifi, M., \& Asgari, N. (2010). Multiple criteria facility location problems: A survey. Applied Mathematical Modelling, 34(7), 1689-1709. https://doi.org/10.1016/j.apm.2009.10.005

Garuti, C., \& Salomon, V. (2012). Compatibility indices between priority vectors. International Journal of the Analytic Hierarchy Process, 4(2), 152-160. https://doi.org/10.13033/ijahp.v4i2.130

Garuti, C. E. (2019). A set theory justification of Garuti's compatibility index. Journal of Multi-Criteria Decision Analysis, 27(2), 50-60. https://doi.org/10.1002/mcda.1667

Grillitsch, M., \& Asheim, B. (2018). Place-based innovation policy for industrial diversification in regions. European Planning Studies, 26(8), 1638-1662. https://doi.org/10.1080/09654313.2018.1484892

Hwang, C.-L., \& Yoon, K. (1981). Multiple attribute decision making. Springer.

Indraprahasta, G. S., Derudder, B., \& Hudalah, D. (2019). Local institutional actors and globally linked territorial development in Bekasi District: A strategic coupling? Singapore Journal of Tropical Geography, 40(2), 219-238. https://doi.org/10.1111/sjtg.12269

Ishizaka, A., \& Nemery, P. (2013). Multi-criteria decision analysis. Wiley.

Jiang, Y., Timmermans, H., \& Yu, B. (2018). Relocation of manufacturing industry from the perspective of transport accessibility: An application of percolation theory. Transport Policy, 63, 10-29. https://doi.org/ 10.1016/j.tranpol.2017.11.003

Johansson, M., \& Olhager, J. (2017). Manufacturing relocation through offshoring and backshoring: The case of Sweden. Journal of Manufacturing Technology Management, 29(4), 637-657. https://doi.org/10.1108/ JMTM-01-2017-0006

Khan, S. A., Chaabane, A., \& Dweiri, F. T. (2018). Multi-criteria decision-making methods application in supply chain management: A systematic literature review. In V. A. Salomon (Ed.), Multi-criteria methods and techniques applied to supply chain management (pp. 3-31). Intech Open.

Koch, N., \& Basse Mama, H. (2019). Does the EU Emissions Trading Systems induce investment leakage? Evidence from German multinational firms. Energy Economics, 81, 479-492. https://doi.org/10.1016/j. eneco.2019.04.018

Kurata, H., Nomura, R., \& Suga, N. (2020). Vertical specialization in North-South trade: Industrial relocation, wage and welfare. Review of International Economics, 28(1), 119-137. https://doi.org/10.1111/roie. 12444 
Lee, C.-Y., \& Chen, B.-S. (2018). Mutually-exclusive-and-collectively-exhaustive feature selection scheme. Applied Soft Computing, 68, 961-971. https://doi.org/10.1016/j.asoc.2017.04.055

Lee, E., Lee, J., \& Jongseok, L. (2006). Reconsideration of the winner-take-all hypothesis: Complex networks and local bias. Management ScienceVol., 52(12), 1838-1848. https://doi.org/10.1287/mnsc.1060.0571

Li, M., \& Wang, Q. (2020). Does industrial relocation alleviate environmental pollution? A mathematical economics analysis. Environmental, Development and Sustainability, 22(5), 4673-4698. https://doi.org/ 10.1007/s10668-019-00403-7

Li, T., Liu, Y., Wang, C., Olfsson, G., Wang, Z., \& Wang, H. (2019). Decentralization of the non-capital functions of Beiijing: Industrial relocation and its environmental effects. Journal of Cleaner Production, 224, 545-556. https://doi.org/10.1016/j.jclepro.2019.03.247

Liao, H. F., \& Chan, R. C. (2011). Industrial relocation of Hong Kong manufacturing firms: Towards an expanding industrial space beyond the Pearl River Delta. GeoJournal, 76(6), 623-639. https://doi.org/ 10.1007/s10708-009-9316-3

Liern, V., \& Pérez-Gladish, B. (2020). Multiple criteria ranking method based on functional proximity index: Un-weighted TOPSIS. Annals of Operations Research. https://doi.org/10.1007/s10479-020-03718-1

Lipovetsky, S. (2020). Priority vector estimation: Consistency, compatibility, precision. International Journal of the Analytic Hierarchy Process, 12(3), 577-591. https://doi.org/10.13033/ijahp.v12i3.801

Liu, Y., Sun, Z., Liang, H., \& Dong, Y. (2021a). Ranking range model in multiple attribute decision making: A comparison of selected methods. Computers \& Industrial Engineering. https://doi.org/10.1016/j.cie. 2021.107180

Liu, Y., Yeung, G., Liang, Y.-T., \& Li, X. (2021). Pro-active regional policy and the relocation of manufacturing firms: A case study of state-led industrial relocation in Guangdong. China: Eurasian Geography and Economics. https://doi.org/10.1080/15387216.2020.1870515

Lombardi Netto, A., Salomon, V. A., Ortiz-Barrios, M. A., Florek-Paszkowska, A. K., Petrillo, A., \& De Oliveira, O. J. (2020). Multiple criteria assessment of sustainability programs in the textile industry. International Transactions in Operational Research, 28(3), 1550-1572. https://doi.org/10.1111/itor.12871

Lundberg, H., Andresen, E., \& Törnroos, J. -Å. (2016). Understanding network emergence after turbulent industrial relocation: A Swedish biorefinery initiative. European Management Journal, 34(5), 475-483. https://doi.org/10.1016/j.emj.2016.03.001

Mardani, A., Jusoh, A., Nor, K. M. D., Khalifah, Z., Zakwan, N., \& Valipour, A. (2015a). Multiple criteria decision-making techniques and their applications: A review of the literature from 2000 to 2014. Economic Research-Ekonomska Istraživanja, 28(1), 516-571. https://doi.org/10.1080/1331677X.2015. 1075139

Mardani, A., Jusoh, A., \& Zavadskas, E. K. (2015b). Fuzzy multiple criteria decision-making techniques and applications: Two decades review from 1994 to 2014. Expert Systems with Applications, 42(8), 4126-4148. https://doi.org/10.1016/j.eswa.2015.01.003

Melo, M. T., Nickel, S., \& Saldanha-da-Gama, F. (2009). Facility location and supply chain management: A review. European Journal of Operational Research, 169(2), 401-412. https://doi.org/10.1016/j.ejor. 2008.05.007

Mu, E., Cooper, O., \& Peasley, M. (2020). Best practices in analytic network process studies. Expert Systems with Applications, 159, 113536. https://doi.org/10.1016/j.eswa.2020.113536

Oliveira, G. D., \& Dias, L. C. (2020). The potential learning effect of a MCDA approach on consumer preferences for alternative fuel vehicles. Annals of Operations Research, 293(2), 767-787. https://doi. org/10.1007/s10479-020-03584-X

Oppio, A., Bottero, M., \& Arcidiacono, A. (2018). Assessing urban quality: a proposal for a MCDA evaluation framework. Annals of Operations Research. https://doi.org/10.1007/s10479-017-2738-2

Ortiz Barrios, M., Cabarcas Reyes, J., Ishizaka, A., Barbati, M., Jaramillo Rueda, N., \& Carrascal Zambrano, G. J. (2020). A hybrid fuzzy multi criteria decision making model for selecting a sustainable supplier of forklift filters: A case study from the mining industry. Annals of Operations Research. https://doi.org/ 10.1007/s10479-020-03737-y

Ortiz-Barrios, M., \& Alfaro-Saiz, J.-J. (2020). A hybrid fuzzy multi-criteria decision-making model to evaluate the overall performance of public emergency departments: A case study. International Journal of Information Technology \& Decision Making, 19(6), 1485-1548. https://doi.org/10.1142/S0219622020500364

Ortiz-Barrios, M., Hoz, C.M.-D., López-Meza, P., Petrillo, A., \& De Felice, F. (2020). A case of food supply chain management with AHP, DEMATEL, and TOPSIS. Journal of Multi-Criteria Decision Analysis, 27(1-2), 104-128. https://doi.org/10.1002/mcda.1693

Pan, Z., Wang, G., Hu, Y., \& Cao, B. (2019). Characterizing urban redevelopment process by quantifying thermal dynamic and landscape analysis. Habitat International, 86, 61-70. https://doi.org/10.1016/j. habitatint.2019.03.004 
Pappas, D., Chalvatzis, K. J., Guan, D., \& Ioannidis, A. (2018). Energy and carbon intensity: A study on the cross-country industrial shift from China to India and SE Asia. Applied Energy, 225, 183-194. https:// doi.org/10.1016/j.apenergy.2018.04.132

Rice, J. A. (2007). Mathematical statistics and data analysis (e-book ed.). Cengage.

Roy, B. (1981). The optimisation problem formulation: Criticism and overstepping. Journal of the Operational Research Society, 32(6), 427-436. https://doi.org/10.1057/jors.1981.93

Saaty, T. L. (1974). Measuring the fuzziness of sets. Journal of Cybernetics, 4(4), 53-61. https://doi.org/10. $1080 / 01969727408546075$

Saaty, T. L. (1977). A scaling method for priorities in hierarchical structures. Journal of Mathematical Psychology, 15(3), 234-281. https://doi.org/10.1016/0022-2496(77)90033-5

Saaty, T. L. (1980). The analytic hierarchy process. McGraw-Hill.

Saaty, T. L. (1986). Absolute and relative measurement with the AHP-The most livable cities in the United States. Socio-Economic Planning Sciences, 20(6), 327-331. https://doi.org/10.1016/00380121(86)90043-1

Saaty, T. L. (2013). Principia mathematica decernendi (Kindle). RWS.

Saaty, T. L., \& Rogers, P. C. (1976). Higher education in the United States (1985-2000) Scenario construction using a hierarchical framework with eigenvector weighting. Socio-Economic Planning Sciences, 10(6), 251-263. https://doi.org/10.1016/0038-0121(76)90012-4

Salomon, V. A. (2016). Absolute measurement and ideal synthesis on AHP. International Journal of the Analytic Hierarchy Process, 3(1), 538-545. https://doi.org/10.13033/ijahp.v8i3.452

Salomon, V. A., \& Rangel, L. D. (2015). Comparing rankings from using TODIM and a fuzzy expert system. Procedia Computer Science, 55, 126-138. https://doi.org/10.1016/j.procs.2015.07.019

Salomon, V. P., Tramarico, C. L., \& Marins, F. S. (2016). Analytic hierarchy process applied to supply chain management. In F. De Felice, T. L. Saaty, \& A. Petrillo (Eds.), Applications and theory of analytic hierarchy process-Decision making for strategic decisions (pp. 1-16). IntechOpen.

Schamp, E. W. (2005). Decline of the district, renewal of firms: An evolutionary approach to footwear production in the Pirmasens area, Germany. Environment and Planning a: Economy and Space, 37(4), 617-634. https://doi.org/10.1068/a36275

Shih, H.-S., Cheng, C.-B., Chen, C.-C., \& Lin, Y.-C. (2014). Environmental impact on the vendor selection problem in electronics firms: A systematic analytic network process with BOCR. International Journal of the Analytic Hierarchy Process, 6(2), 202-227. https://doi.org/10.13033/ijahp.v6i2.256

Tang, T., Li, Z., Ni, J., \& Yuan, J. (2020). Land costs, government intervention, and migration of firms: The case of China. China Economic Review. https://doi.org/10.1016/j.chieco.2020.101560

Tramarico, C. L., Mizuno, D., Salomon, V. P., \& Marins, F. S. (2015). Analytic hierarchy process and supply chain management: A bibliometric study. Procedia Computer Science, 55, 441-450. https://doi.org/10. 1016/j.procs.2015.07.005

Vaidya, O. S., \& Kumar, S. (2006). Analytic hierarchy process: An overview of applications. European Journal of Operational Research, 169(1), 1-29. https://doi.org/10.1016/j.ejor.2004.04.028

Venables, W. N., \& Ripley, B. D. (2002). Modern applied statistics with $S$ (4th ed.). Springer.

Wallenius, J., Dyer, J. S., Fishburn, P. C., Steuer, R. E., Zionts, S., \& Deb, K. (2008). Multiple criteria decision making, multiattribute utility theory: Recent accomplishments and what lies ahead. Management Science, 54(7), 1336-1349. https://doi.org/10.1287/mnsc.1070.0838

Wang, H., Dong, C., \& Liu, Y. (2019). Beijing direct investment to its neighbors: A pollution haven or pollution halo effects? Journal of Cleaner Production. https://doi.org/10.1016/j.jclepro.2019.118062

Wang, Y. (2015). A fuzzy multi-criteria decision-making model based on simple additive weighting method and relative preference relation. Applied Soft Computing, 30, 412-420. https://doi.org/10.1016/j.asoc. 2015.02.002

Whitaker, R. (2007). Validation examples of the analytic hierarchy process and analytic network process. Mathematical and Computer Modelling, 46(7-8), 840-859. https://doi.org/10.1016/j.mcm.2007.03.018

Wijnmalen, D. J. (2007). Analysis of benefits, opportunities, costs, and risks (BOCR) with the AHP-ANP: A critical validation. Mathematical and Computer Modelling, 46(7-8), 892-905. https://doi.org/10.1016/ j.mcm.2007.03.020

Wikimedia Commons. (2008) Brazil Blank Map light.svg. Retrived June 18, 2021, from https://images.app. goo.gl/ij5mSUQxJJ57p8gx6

Wu, A., Li, G., Sun, T., \& Liang, Y. (2014). Effects of industrial relocation on Chinese regional economic growth disparities: Based on system dynamics modeling. Chinese Geographical Science, 24, 706-716. https://doi.org/10.1007/s11769-014-0664-7

Yang, Y., \& Gallagher, M. (2017). Moving in and moving up? Labor conditions and China's changing development model. Public Administration and Development, 37(3), 160-175. https://doi.org/10.1002/pad. 1818 
Yoon, M.-S. (2020). Notes on the use of compatibility index in the analytic hierarchy process. In: Proceedings of the International Symposium on the Analytic Hierarchy Process. https://doi.org/10.13033/isahp. y2020.047

Zamani-Sabzi, H., King, J. P., Gard, C. C., \& Abudu, S. (2016). Statistical and analytical comparison of multi-criteria decision-making techniques under fuzzy environment. Operations Research Perspectives, 3, 92-117. https://doi.org/10.1016/j.orp.2016.11.001

Zanakis, S. H., Solomon, A., Wishart, N., \& Dublish, S. (1998). Multi-attribute decision making: A simulation comparison of select methods. European Journal of Operational Research, 107(3), 507-529. https://doi. org/10.1016/S0377-2217(97)00147-1

Zavadskas, E. K., Turskis, Z., \& Kildienè, S. (2014). State of art surveys of overviews on MCDM/MADM methods. Technological and Economic Development of Economy, 20(1), 165-179. https://doi.org/10. 3846/20294913.2014.892037

Zhang, L., Meng, Q., Sun, Z., \& Sun, Y. (2017). Spatial and temporal analysis of the mitigating effects of industrial relocation on the surface urban heat island over China. International Journal of GeoInformation, 6(4), 1-14. https://doi.org/10.3390/ijgi6040121

Zhang, W., Zhang, X., Zhang, M., \& Li, W. (2020). How to coordinate economic, logistics and ecological environment? Evidences from 30 provinces and cities in China. Sustainability, 12(3), 1-23. https://doi. org/10.3390/su 12031058

Zhang, X., Xu, Z., \& Wang, H. (2015). Heterogeneous multiple criteria group decision making with incomplete weight information: A deviation modeling approach. Information Fusion, 25, 49-62. https://doi.org/10. 1016/j.inffus.2014.10.006

Publisher's Note Springer Nature remains neutral with regard to jurisdictional claims in published maps and institutional affiliations. 